\title{
PRINCÍPIOS DA CARTOGRAFIA E O PENSAMENTO DA DIFERENÇA EM DELEUZE - O QUE QUER A PESQUISA CARTOGRÁFICA?
}

\section{PRINCIPLES OF CARTOGRAPHY AND THE THOUGHT OF THE DIFFERENCE IN DELEUZE - WHAT DOES THE CARTOGRAPHIC RESEARCH WANT?}

\section{PRINCIPIOS DE LA CARTOGRAFÍA Y EL PENSAMIENTO DE LA DIFERENCIA EN DELEUZE - QUÉ QUIERES LA INVESTIGACIÓN CARTOGRÁFICA?}

\author{
CUNHA, Claudia Madruga \\ claudiamcunha@ufpr.br \\ Universidade Federal do Paraná \\ http://orcid.org/0000-0002-2867-5566
}

\begin{abstract}
RESUMO Para Gilles Deleuze, o conceito de diferença trata da matéria do sensível. Refletir a diferença conjetura o pensar e o ainda não fundado do pensamento. A diferença, nessa perspectiva, deixa de ser oposição a identidade (epistemologia moderna) ou análoga a diversidade. Ao mesmo tempo, exige propor outra imagem para pensar, evitando refundar uma imagem de mundo. A descrição dos princípios do rizoma implica em um novo formato de escrever, narrar, pesquisar, tendo por plano de composição a diferença. Deleuze, reunido a Felix Guattari em Mil platôs, lista princípios que contribuem para entender o que quer a pesquisa cartográfica.
\end{abstract}

Palavras-chave: Cartografia. Desconstrução. Educação. Filosofias da diferença.

ABSTRACT For Gilles Deleuze the concept of difference deals with the matter of the sensible. Reflecting the difference conjectures the thinking and the yet unfounded of the thought. The difference, from this perspective, ceases to be opposition to identity (modern epistemology) or analogous to diversity. At the same time it demands to propose another image to think, avoiding to refound an image of the world. The description of the principles of the rhizome implies a new format of writing, narrating and researching by having as composition plan the difference. Deleuze, together with Felix Guattari in Mil Platos, lists principles that contribute to understanding what cartographic research wants.

Keywords: Cartography. Deconstruction. Education. Philosophies of difference.

RESUMEN Para Gilles Deleuze el concepto de diferencia trata de la materia de lo sensible. Reflejar la diferencia conjetura el pensar y el todavía no fundado del pensamiento. La diferencia, en esa perspectiva, deja de ser oposición a la identidad (la epistemología moderna) o análoga a la diversidad. Al mismo tiempo exige proponer otra imagen para pensar, evitando refundar una imagen de mundo. La descripción de los principios del rizoma implica en un nuevo formato de escribir, narrar, investigar teniendo por plano de composición la diferencia. Deleuze, reunido a Felix Guattari, en Mil Platos, lista principios que contribuyen a entender lo que quiere la investigación cartográfica.

Palabras clave: Cartografía. Deconstrucción. Educación. Filosofías de la diferencia. 


\section{Atos de Pesquisa em Educação - ISSN 1809-0354 \\ Blumenau, v.14, n.3, p.934-959, set./dez. 2019 \\ DOI: http://dx.doi.org/10.7867/1809-0354.2019v14n3p934-959}

935

\section{INTRODUÇÃO}

Várias questões suscitadas pelo contexto sociopolítico e cultural atual têm convocado as áreas da filosofia, das artes, da educação, entre outras, ao trabalho que envolve a análise das realidades, processos, modos de ser e de existir que implicam a diferença, conceito muitas vezes confundido com o de diversidade. Apesar de haver alguma analogia entre ambos e seu sentido, decididamente eles não fundam a mesma coisa - seja essa coisa existência, aparência ou modo de ser daquilo que, sendo existente, evoca o sensível.

Quando se busca no Google 1 um sinônimo para "diversidade", encontram-se três (3) sentidos possíveis. O primeiro entende a diversidade como algo assemelhado a diferença, desigualdade, dessemelhança, discrepância, disparidade, dissemelhança, distinção, heterogeneidade, dessemelhação; o segundo compreende como discordância, atraindo a noção de divergência, contradição, desacordo; e o terceiro pode remeter a multiplicidade, convidando as noções de pluralidade, variedade, abundância e sortimentos como pares. Se no mesmo dicionário colocarmos a palavra "diferença", vamos encontrar dez (10) sentidos diferentes e 57 sinônimos, que não cabe descrever aqui. Essa busca pelo sinônimo de duas palavras ou conceitos que costumam andar juntos permite uma espécie de introdução, recorte ou ponto de partida para se pensar que diversidade e diferença não são o mesmo.

A diferença, em Gilles Deleuze, é conceito que trata antes de mais nada da matéria do sensível, de algo que se produz, na linguagem, por exemplo, entre o isso e o aquilo de um sistema binário, na fissura "entre", que "[...] não é nem interior nem exterior, ela se acha na fronteira, insensível, incorporal, ideal” (DELEUZE, 1974, p.158). Em que medida esse conceito que comumente se associa e se aproxima da diversidade remete realmente a ela em maior ou menor grau, quando se trata de uma filosofia que busca construir uma ontologia da diferença e nessa busca pode ser entendida por seus intérpretes de vários modos? Hardt (1996) a tratou como filosofia pós-estruturalista; Gil (2008) e Zourabichvili $(2005,2016)$ dizem que Deleuze produziu 


\section{Atos de Pesquisa em Educação - ISSN 1809-0354 \\ Blumenau, v.14, n.3, p.934-959, set./dez. 2019 \\ DOI: http://dx.doi.org/10.7867/1809-0354.2019v14n3p934-959}

uma filosofia da imanência; Machado (2010), que o filósofo construiu uma filosofia das relações; Dias (2012) chamou de filosofia do acontecimento; em estudos que se realizam no Brasil foi nominada de Filosofia Rizoma (CUNHA, 2011). Mais recentemente,Lapoujade (2015), refutou a ideia de que a filosofia deleuziana seja uma filosofia da imanência ou do acontecimento. Ele a interpreta como filosofia dos movimentos aberrantes. Essas diferentes acepções derivam ou dialogam com os princípios propostos em Mil platôs I (DELEUZE; GUATTARI,1995).

No primeiro texto de Mil platôs I, Deleuze e Guattari (1995, p. 11) afirmam "que um livro não tem objeto nem sujeito; é feito de matérias diferentemente formadas, de datas e velocidades muito diferentes". De acordo com eles, um livro, quando atribuído a um sujeito,negligencia o construto das matérias e a exterioridade de suas correlações. Dizer que em um livro ou em outro texto os conteúdos postos em linguagem escrita não derivam apenas das racionalidades dos sujeitos significa dizer que o que se expressa em uma narrativa descreve "[...] linhas de articulação ou segmentariedade, estratos, territorialidades, mas também linhas de fuga, movimentos de desterritorialização e desestratificação" (DELEUZE; GUATTARI, 1995, p.11). Um livro, uma escrita, uma pesquisa expressam o agenciamento de linhas e de velocidades mensuráveis, um procedimento ou uma maneira como algo é feito num processo de múltiplos sentidos. Um livro é uma pequena máquina feita de muitas máquinas que, conectadas, mostram um funcionamento.

Parece claro que nessa obra os autores buscam uma outra imagem do pensamento, um caminho por onde propor novos conhecimentos que não passe por fundar saberes ao modo de árvore que referencia uma imagem de mundo. A descrição dos princípios do rizoma implica em um novo formato de escrever, narrar, pesquisar. "Escrever não tem nada a ver com significar, mas com agrimensar, cartografar, mesmo que sejam regiões por vir" (DELEUZE; GUATTARI, 1995, p.13). Após uma leitura da introdução de Mil platôs, faz sentido o que diz Lapoujade:oque Deleuze busca em toda sua obra é a criação de uma lógica, mas essa procura tem algo de curioso quando implica em "[...]um movimento que é tanto mais lógico quanto mais escapa a toda racionalidade". (LAPOUJADE,2015, p.13). 


\section{Atos de Pesquisa em Educação - ISSN 1809-0354 \\ Blumenau, v.14, n.3, p.934-959, set./dez. 2019 \\ DOI: http://dx.doi.org/10.7867/1809-0354.2019v14n3p934-959}

Quando essa filosofia trata a diferença como instância ontológica, ela a distingue dos sentidos que estão análogos, de algum modo, nas questões da diversidade e nas representações que as implicam. Na ideia de manter os processos que tratam da diferença em movimento de diferenciação, Deleuze e Guattari(1995) aproximam a diferença da/s multiplicidade/s e o conceito de multiplicidade de algo que se movimenta o tempo todo, em torno das conexões que consegue fazer entre as dimensões que Ihe pertencem. Tais dimensões, numa organização própria do múltiplo, nunca chegam a formar sistema (DELEUZE, 2000a).

As multiplicidades em Gilles Deleuze aludem às noções de dualismos, paradoxos, proliferação de sentido, séries heterogêneas, singularidades, acontecimentos, dimensões, entre outros conceitos presentes em Diferença $e$ repetição (DELEUZE, 2000a) e em Lógica do sentido (DELEUZE, 1974), obras anteriores a Mil platôs. De um lado, esse conceito bergsoniano opera, parafraseando Zourabichvili (2004), fazendo com que a oposição entre uno e múltiplo deixe de ser pertinente; de outro lado, permite distinguir dois tipos de multiplicidade: uma atual e extensiva e outra virtual e intensiva. As multiplicidades que referem a certa unidade da diferença equivalem em ambos os lados a n-1. Essa unidade é parte sempre subtraída sobre a qual não se acrescenta uma dimensão superior, mas dimensões que a dispõem.

\section{PRINCÍPIOS DA CARTOGRAFIA}

Os princípios da cartografia estão a serviço de uma lógica irracional, na qual o mundo perdeu seu pivô e o sujeito já não pode fazer sequer dicotomia, embora acesse uma alta unidade de ambivalência e sobredeterminação na dimensão suplementar que implica seu objeto. Esses princípios indicam a possibilidade de se fazer um processo com o múltiplo sem acrescentar uma dimensão superior e propõem o -1 (menos um), a subjetividade e a objetividade, subtraídas da multiplicidade. Nada existe de forma pré-individual ou pré-formal. Lapoujade, citando Zourabichvili, diz que em Deleuze o irracional não é sinônimo de ilógico. 


\section{Atos de Pesquisa em Educação - ISSN 1809-0354 \\ Blumenau, v.14, n.3, p.934-959, set./dez. 2019 \\ DOI: http://dx.doi.org/10.7867/1809-0354.2019v14n3p934-959}

[...]do início ao fim as lógicas que lhe interessam são as que escapam a qualquer razão, lógica do masoquismo, lógica do sentido e do não sentido em Lewis Carrol, lógica do processo esquizofrênico ou, ainda, a lógica de determinados filósofos bem pouco racionais (Hume, Bergson, Espinosa, e até Leibniz). Em Deleuze a lógica tem sempre algo de esquizofrênico. (LAPOUJADE, 2015, p.13).

Se em Deleuze lógico não quer dizer racional, aparentemente a cartografia e/ou o rizoma andam na superfície e anunciam as questões de um problema empírico.Esse empírico diz também de uma esquizofrenia cuja apresentação traz à tona o inconsciente e reduza representação da consciência - ou não fala apenas dela. Essa força ou potência que vem do subjetivo e força a sair das evidências da consciência para propor um exercício discordante que penetra ou se deixa penetrar pelos processos inconscientes. Nesse sentido, o irracional é uma potência para o pensamento.

Os primeiros princípios do rizoma querem preparar um modo possível de se sair das faculdades do bom senso e do senso comum, na retomada de uma multiplicidade ligada a torção ou paradoxo. O paradoxo opõe a diferença à identidade quando entende acessar um conhecimento que tanto penetra a ideia, as matérias e os conceitos, como os desdobra em suas variedades e pontos notáveis para fazer um exercício de um transcendente que é disjuntivo. As teorias do acaso e da multiplicidade, da repetição e do retorno do mesmo, das séries, são exercícios prévios aos princípios do rizoma.

O primeiro princípio, o da conexão, e o segundo, da heterogeneidade, convergem para se pensar o caos e o aleatório. Assim como as teorias do acontecimento, das séries, da origem da linguagem, do jogo ideal vão sugerir um processo de atualização. E se aproximarmos esses elementos da singularidade, conceito muito próximo ao de individuação (SIMONDON, 2003), pode-se pensar que criar algo singular em termos de pesquisa tem a ver com se colocar como captador ou agenciador do movimento de cadeias semióticas, através das quais se lança os dados para construir um caso sobre a circulação das organizações de poder, outros episódios e passagens que, remetendo à arte, às ciências e às lutas sociais, informam 


\section{Atos de Pesquisa em Educação - ISSN 1809-0354 \\ Blumenau, v.14, n.3, p.934-959, set./dez. 2019 \\ DOI: http://dx.doi.org/10.7867/1809-0354.2019v14n3p934-959}

em suas diferentes linguagens e ao modo de um descentramento quais dimensões são passíveis de registro.

A própria linguagem aponta para não audiência de um locutor ou auditor ideal, dizemDeleuze e Guattari, pois não existe uma comunidade linguística homogênea. Entendem que não existe uma língua mãe, "mas tomada de poder por uma língua dominante dentro de uma multiplicidade política". (DELEUZE; GUATTARI, 1995, p.16). Esses dois princípios fazem pensar que aquele que pesquisa a diferença ou os temas da diferença tem que se colocar no lugar de decompositor de estruturas internas, o que às vezes significa buscar raízes, algo genealógico, como apontam os autores. Entretanto, um método de tipo rizoma leva a efetuar um descentramento da própria linguagem em outras dimensões e registros. Portanto, os autores concluem que uma língua não se fecha sobre si mesma, senão em função de uma impotência.

O terceiro princípio tensiona a tênue relação entre diferença e multiplicidade. $O$ rizoma é "multiplicidade composta de dimensões que se englobam umas às outras, cada uma recapturando todas as outras em um outro grau, segundo uma lista aberta que pode ser acrescida de novas dimensões". (ZOURABICHVILI, 2004, p.38). Feito de dimensões, o "[...] rizoma é portanto um antimétodo que parece tudo autorizar[...]". (ZOURABICHVILI, 2004, p.52). Tais dimensões não têm início nem fim, mas um meio, no qual a ideia da gênese mostra-se como um devir. A multiplicidade, portanto, referese ao fato de que ela própria é constituinte do rizoma. Segundo Lapoujade (2015), Milplatôs é a obra das multiplicidades, que nela são sujeito e são objeto do livro. Feita de determinações e grandezas, a multiplicidade envolve

[...]dimensões que não podem crescer sem que mude de natureza (as leis de combinação crescem então com a multiplicidade). Os fios da marionete, considerados como rizoma ou multiplicidade, não remetem à vontade suposta una de um artista ou de um operador, mas à multiplicidade das fibras nervosas que formam por sua vez uma outra marionete, seguindo outras dimensões conectadas às primeiras. (DELEUZE; GUATTARI, 1995, p.4).

Os autores explicam o agenciamento, conceito que já estava na Lógica do sentido, como sendo aquele que refere às dimensões da multiplicidade, que mudam necessariamente de natureza à medida que o rizoma aumenta suas conexões. Não 


\section{Atos de Pesquisa em Educação - ISSN 1809-0354 \\ Blumenau, v.14, n.3, p.934-959, set./dez. 2019 \\ DOI: http://dx.doi.org/10.7867/1809-0354.2019v14n3p934-959}

existem num rizoma pontos ou posições como se encontra numa estrutura, numa árvore, numa raiz. Existem somente linhas (DELEUZE; GUATTARI, 1995). O rizoma que pode ser compreendido como um instrumento da cartografia e vice-versa

[...]refere a um mapa que deve ser produzido, construído, sempre desmontável, conectável, reversível, modificável, com múltiplas entradas e saídas, com suas linhas de fuga. São os decalques que é preciso referir aos mapas e não o inverso. Contra os sistemas centrados (e mesmo policentrados), de comunicação hierárquica e ligações preestabelecidas, o rizoma é um sistema a-centrado não hierárquico e não significante, sem General, sem memória organizadora ou autômato central, unicamente definido por uma circulação de estados. (DELEUZE; GUATTARI,1995, p.15).

Já o quarto princípio é o da ruptura a-significante e fala contra os cortes demasiado significantes que separam as estruturas, ou que atravessam uma estrutura. Um rizoma pode ser rompido, quebrado em um lugar qualquer, e também retomado seguindo uma ou outra de suas linhas e seguindo outras linhas. Esse quarto princípio inclui o tema das linhas e diz que todo "rizoma compreende linhas de segmentaridade segundo as quais ele é estratificado, territorializado, organizado, significado, atribuído". (DELEUZE; GUATTARI, 1995, p.6). Abrange também as linhas de desterritorialização através das quais pode fugir sem parar. Ao falar da ruptura, os autores apontam para linhas segmentares que podem explodir numa linha de fuga. As linhas de fuga são parte do rizoma e não param de se remeter uma às outras.

O interessante da linha de fuga é que ela dialoga com o devir ou com o estado de limiar, linha limite, fissura, que se encontra em muitas passagens de Diferença e repetição e também de Lógica do sentido. A linha de fuga implica as subjetividades e os devires e é aquela sob a qual uma ruptura acontece num processo tal que corre o risco de encontrar nela as organizações, formações e outras formas de poder "[...] que invadem o físico e psíquico dos grupos e do indivíduo. Os grupos e os indivíduos contêm microfascismos sempre à espera de cristalização. Sim, a grama é também rizoma. O bom e o mau são somente o produto de uma seleção ativa e temporária a ser recomeçada". (DELEUZE; GUATTARI, 1995, p.6).

O quinto e o sexto princípios do rizoma tratam da reafirmação da cartografia e da decalcomania. Sempre preocupados em se diferenciar da filosofia da tradição, os 


\title{
Atos de Pesquisa em Educação - ISSN 1809-0354 \\ Blumenau, v.14, n.3, p.934-959, set./dez. 2019 \\ DOI: http://dx.doi.org/10.7867/1809-0354.2019v14n3p934-959
}

autores dizem que "um rizoma não pode ser justificado por nenhum modelo estrutural ou gerativo. Ele é estranho a qualquer ideia de eixo genético ou de estrutura profunda". (DELEUZE; GUATTARI, 1995, p.7). Traduzem por eixo genético ou estrutura profunda princípios de decalque, reprodutíveis ao infinito. Dizem que

\begin{abstract}
Toda lógica da árvore é uma lógica do decalque e da reprodução. Tanto na Lingüística quanto na Psicanálise, ela tem como objeto um inconsciente, ele mesmo representante, cristalizado em complexos codificados, repartido sobre um eixo genético ou distribuído numa estrutura sintagmática.[...]. A árvore articula e hierarquiza os decalques, os decalques são como folhas da árvore. Diferente é o rizoma, mapa e não decalque. Fazer o mapa, não o decalque. A orquídea não reproduz o decalque da vespa, ela compõe um mapa com a vespa no seio de um rizoma. Se o mapa se opõe ao decalque é por estar inteiramente voltado para uma experimentação ancorada no real. $O$ mapa não reproduz um inconsciente fechado sobre ele mesmo, ele o constrói. Ele contribui para a conexão dos campos, para o desbloqueio dos corpos sem órgãos, para sua abertura máxima sobre um plano de consistência. Ele faz parte do rizoma. (DELEUZE; GUATTARI,1995, p.8).
\end{abstract}

Por fim, elogiam o mapa, mostram que é aberto e, sendo aberto, permite as conexões entre suas dimensões. Também é desmontável, reversível, suscetível de receber modificações constantemente. Para além de enfrentar a ruptura, pode ser rasgado, revertido, adaptar-se a montagens de qualquer natureza, ser preparado por um indivíduo, um grupo, uma formação social. Pode-se desenhá-lo numa parede, concebê-lo como obra de arte, construí-lo como uma ação política ou como uma meditação. (DELEUZE; GUATTARI, 1995, p.8).

\section{PENSAR A DIFERENÇA}

No ano de 1988, ao responder a entrevistadores da Magazine Littéraire, Deleuze (cf. 1992)rememora que seu percurso como filósofo passou por três fases. A primeira foi aquela em que fez estudos sobre autores da história da filosofia, estudos que para ele tendiam a uma grande identidade Espinoza-Nietzsche. A segunda foi a de criação da própria filosofia, fase de encontro com Felix Guattari, na qual escrevem Anti-Oedipus e Mille Plateaux²; e a terceira e última fase é a que trata da pintura, do cinema e das imagens, sempre fazendo filosofia.

2 Foram editadas na França, por isso aqui utilizamos os títulos originais em francês. 


\section{Atos de Pesquisa em Educação - ISSN 1809-0354 \\ Blumenau, v.14, n.3, p.934-959, set./dez. 2019 \\ DOI: http://dx.doi.org/10.7867/1809-0354.2019v14n3p934-959}

Retomando alguns de seus estudos sistemáticos, o filósofo iniciou o projeto de construir uma filosofia própria, que culmina com o aparecimento da obra Diferença e repetição, em 1968. Pode-se perceber a partir desse livroa tentativa de elaboração de uma ontologia, o que vai atravessando suas obras posteriores. Essa ontologia se ocupa de tirar a diferença de uma espécie de maldição que a liga às forças do mal, ao erro, ao pecado e à monstruosidade. Tal maldição foi posta pela tradição que vem de Platão (DELEUZE, 2000a) e chega ao ápice com Immanuel Kant (DELEUZE, 2000b)3.

A filosofia da tradição fala da relação entre a consciência do que se passa e o que se passa na consciência, numa tendência de admitir uma correspondência entre sujeito e objeto. Envolve uma espécie de acordo com o qual se organiza a ordem das ideias e a ordem das coisas. Em A filosofia crítica de Kant, Deleuze (2000b) mostra que o filósofo das críticas entende o espaço e o tempo como conceitos a priori, como categorias das quais se deduz o juízo. Aquilo que é dado na experiência é superado na nossa subjetividade em função de que dispomos desses princípios; pois o dado não pode superar a operação pela qual é apreendido. Nisso, Kant está de acordo com Hume.

Entretanto, Hume (DELEUZE, 2001) entendia que os princípios psicológicos são princípios da natureza humana, associações respeitantes ao fato de se lidar com as representações. Posterior à de Hume, a filosofia kantiana faz do transcendental e dos princípios a prioriprocedimentos subjetivos nos quais os dados da natureza devem obedecer aos seus princípios, entre eles o de gênero, que passa a regular o curso das representações. Resumindo, o a priori em Kant é legitimado de tal modo que passa a

\footnotetext{
${ }^{3}$ Ao fazer a crítica de uma imagem do pensamento dogmático que vem tradição filosófica, a análise de Gilles Deleuze passa por muitos filósofos do pensamento clássico, como Platão e Aristóteles, e pelos modernos: Descartes, Kant, Hegel, entre outros (cf. capítulo 3. In: Diferença e repetição. Tradução de:ORLANDI, I.; MACHADO, R.Lisboa: Relógio D'Água, 2000a). Como este artigo trata dos princípios da cartografia, por uma questão de recorte optou-se por trazer à discussão mais acentuadamente as posições deleuzianas em relação à teoria kantiana, filosofia que, na modernidade, funda princípios sobre o conhecimento.
} 


\section{Atos de Pesquisa em Educação - ISSN 1809-0354 \\ Blumenau, v.14, n.3, p.934-959, set./dez. 2019 \\ DOI: http://dx.doi.org/10.7867/1809-0354.2019v14n3p934-959}

operar aplicando as representações à natureza, mesmo que origine representações que não vêm da natureza.

$\mathrm{Na}$ filosofia moderna, portanto, conhecer implica em tomar algo por consciente sob o jugo das representações, e nas representações, ou através delas, identificar a pertença das ligações que formam a unidade da consciência. Opondo-se a Kant, Deleuze afirma que "as representações não estão unidas numa consciência sem que o diverso que sintetizam esteja no mesmo passo referido a objeto qualquer". (DELEUZE, 2000b, p.23). Como o diverso se refere a objeto que vem da objetividade, a forma que ele possui encontra correlato ou é "correlato do Eu penso ou da unidade da consciência". (DELEUZE, 2000b, p.23).

$\mathrm{Na}$ defesa de uma diferença que não subsuma ao cogito kantiano, a diferença em Deleuze não quer remeter à forma do objeto na imaginação nem ao entendimento na memória, como queria Kant. É preciso esclarecer que quando se entende a diferença como oposição à identidade, está se predicando uma relação em que os fenômenos não são submetidos à imaginação, mas a um tipo de entendimento legislador que faz dela algo negativo sobre os espaços-tempos do interior de uma consciência (DELEUZE, 2000a). A questão é: como levar em frente essa ideia de que a diferença é algo afirmativo, fazendo dela uma objetividade que se afirma em si mesma, sem que para isso se faça uso de pressupostos a priori?

Surge por aí a necessidade de uma ontologia que fuja aos moldes da tradição. A tese de Deleuze busca a construção dessa ontologia da diferença, que:

[...] lembra um lançar de dados. Ela não tem um estatuto de pedestal para se apoiar ou recostar, mas de um devir aleatório, de uma abertura. Os pontos singulares estão no dado; as perguntas são os próprios dados; o imperativo é lançar. As idéias são as combinações problemáticas que resultam dos lances (DELEUZE,2001apudDOSSE, 2010, p.133).

Pensar a diferença envolve a questão de saber se é possível uma ontologia que prescinda da relação entre sujeito e objeto. Dosse (2010) entende que essa relação é ressignificada no conceito de lance de dados, no qual a natureza (o acaso) e o sujeito remetem aodesposamentode um "eu" fendido entre o físico e o psíquico, que distribui a diferença e tende a deslocar nas linhas dessa fenda a ordem da 


\section{Atos de Pesquisa em Educação - ISSN 1809-0354 \\ Blumenau, v.14, n.3, p.934-959, set./dez. 2019 \\ DOI: http://dx.doi.org/10.7867/1809-0354.2019v14n3p934-959}

temporalidade na qual a repetição do diferente acontece. Essa tese deleuziana partilha do monismo espinozista, acrescentando-Ihe a torção de Nietzsche. E nela a diferença passa a não corresponder a nenhuma ordem anterior, embora se repita em função do eterno retorno nietzschiano. O eterno retorno é uma forma de afirmar o acaso, na repetição do pensamento que se ocupa com o singular.

Os princípios da cartografia vão em parte tentar atender as demandas dessa ontologia, que ficou com alguns pontos soltos, frouxos demais. Seriam os princípios um investimento em uma lógica não racional (LAPOUJADE, 2015) que, de algum modo, ficou incompleta? O percurso posterior da obra de Deleuze desdobra esse tensionamento. Disse Machado (2010), ao refletir sobre o que foi considerado por Michel Foucault em artigo que analisa as obras Diferença e repetição e Lógica do sentido:

que a ideia de criação de outro espaço do pensamento filosófico, que já aparece nos livros, é bem mais perceptível nos livros temáticos que, centrados nas questões da diferença, do sentido e do desejo, da multiplicidade, da relação entre os tipos de pensamento, estendem ressonâncias aos saberes científicos, literários e artísticos, sempre com o objetivo de se opor à imagem de pensamento. (MACHADO, 2010, p.25).

Machado (2010) sugere que em toda a obra de Deleuze fica delineada uma oposição entre dois espaços de pensamento: o pensamento da tradição e sua imagem, ligada à herança platônica (arbórea, eurocêntrica hierárquica), que vai sendo substituído por um pensamento sem imagem, que surge, se espraia e acontece na superfície (rizomática, esparramada, rabiscada sobre processos em movimento). Essa noção de pensamento como espaço favorece pensar a cartografia, como um plano no qual se estendem as inquietações de uma pesquisa que busca saber o que ainda não consegue elaborar sobre a extensão das multiplicidades possíveis e intercambiáveis entre pensamento e vida.

Do ponto de vista das estratégias de investigação, a cartografia aposta no acesso ao plano que reúne lado a lado a diversidade de vetores heterogêneos implicados na pesquisa: o pesquisador e seu campo de interlocuções acadêmicas e instrumentos técnicos, agências de fomento, compromissos políticos, alianças institucionais, bem como o objeto e suas diversas articulações. Tal plano é dito comum não por ser homogêneo ou por reunir atores (sujeitos e objetos; humanos e não humanos) que manteriam entre si 


\section{Atos de Pesquisa em Educação - ISSN 1809-0354 \\ Blumenau, v.14, n.3, p.934-959, set./dez. 2019 \\ DOI: http://dx.doi.org/10.7867/1809-0354.2019v14n3p934-959}

relações de identidade, mas porque opera comunicação entre singularidades heterogêneas, num plano que é pré-individual e coletivo. (KASTRUP;PASSOS, 2013, p.265).

Pensar a diferença impõe pensar o impensado. Não implica o que já foi dito, mas o que está por dizer sobre, seja indivíduo, pessoa, grupo. O diferente relacionase com o acontecimento e a uma análise da diferença, à localização de processos onde circulam indivíduo, pessoa, grupo, estados de ser. Tal análise se faz com o que foge aos modos de comunicação universal, que, em geral, antecipam o que acontece. A diferença não é em si em seu ser, mas em seus modos de devir; não é algo que se deixe reduzir a qualquer oposição. As incompatibilidades da diferença são alógicas.

[...]o incompatível não nasce com os indivíduos, as pessoas e os mundos em que os acontecimentos se efetuam, mas não entre os próprios acontecimentos ou suas singularidades acósmicas impessoais e préindividuais. O incompatível não está entre dois acontecimentos, mas entre um acontecimento e o mundo ou o indivíduo que efetuam o acontecimento como divergente. (DELEUZE, 1974, p.183).

O conceito de acontecimento possui um papel fundamental de trazer à tona as circunstâncias empíricas entre as quais a experiência toma o sentido, ou unifica em um sentido, todo um conjunto possível disponível ao entendimento. O acontecimento é o sentido da linguagem e o que se encarna em um estado de coisas. É o futuro e o passado em um mesmo presente.

\section{FUNDAR A DIFERENÇA - NEM SUJEITO NEM OBJETO}

$\mathrm{Na}$ tradição filosófica revisitada por Deleuze, o ser como existente remete, enquanto unidade transcendental, ao ente a priori. Envia a espécie de pré-existência do que existe, permitindo fundar a existência antes da experiência. Deleuze (2000a), na busca de fundar a diferença, substitui a noção de unidade pela de univocidade. Utilizando Bergson, esclarece que a univocidade não é poder dizer do Ser em um único e mesmo sentido. Não há um sentido prévio e único ou um mesmo sentido, que encontre as diferenças individuantes ou as modalidades intrínsecas. Logo, não há um 


\section{Atos de Pesquisa em Educação - ISSN 1809-0354 \\ Blumenau, v.14, n.3, p.934-959, set./dez. 2019 \\ DOI: http://dx.doi.org/10.7867/1809-0354.2019v14n3p934-959}

946

único e mesmo ser, mas entes múltiplos e diferentes produzidos por uma síntese disjuntiva. (ZOURABICHVILI, 2004).

O conceito de univocidade provoca uma noção da diferença e impacienta uma filosofia da diferença. Disse Deleuze sobre a concepção bergsoniana: "Uma tal filosofia opera sempre dois planos: metodológico e ontológico" (DELEUZE, 2010, p.47). O plano metodológico determina que a diferença esteja entre as coisas e o plano ontológico mostra que o ser das coisas está entre outras coisas, em suas diferenças de natureza. No texto $A$ concepção da diferença em Bergson, Deleuze mostra que "o problema da diferença de natureza e o da natureza da diferença" (DELEUZE, 2010, p.48) é a grande sacada da filosofia bergsoniana. Nesse estudo sobre Bergson(DELEUZE,1999)dirá que há uma noção de diferença de natureza entre as coisas que nos provoca a pensar que não pode haver uma diferença interna derivativa. As diferenças de natureza estão entre as coisas; a percepção conduz a ideia de diferença interna, e não o contrário.

Ora, se "a vida é o processo da diferença" (DELEUZE, 2010,p.56), quando a diferença se torna a própria coisa vivida não recebe uma finalidade de fora. A palavra diferença, diz Deleuze, traz o particular que é o novo que se faz. E o traz num processo intuitivo, que guarda por impulso vital algo que dura na memória. Fazer filosofia é começar pela diferença. (DELEUZE, 2010, p.70).

Logo, conhecer, pesquisar, problematizar a realidade implica em se colocar entre planos - metodológico e ontológico - que se bifurcam e se atravessam, que se reúnem no plano cosmológico de Bergson (DELEUZE, 2010). Manter a diferença em estado de diferenciação requer recorrer a outro conceitobergsoniano, a síntese disjuntiva. Essa síntese, diferente da síntese kantiana, opera entre aquilo que compõe a diferença de natureza e a natureza da diferença através de uma série bifurcante e ramificada, que, em meio a um mundo, afirma uma natureza e funda momentaneamente outra.

Essa síntese disjuntiva traz sobre a bifurcação da passagem de um estado a outro uma afirmação que se dá pelo eterno retorno e implica o indivíduo no seu próprio acontecimento. Afirmar a diferença é dizer que tudo está sempre diferindo em tudo na natureza.A duração é que faz com que os movimentos da matéria retornem em graus 


\section{Atos de Pesquisa em Educação - ISSN 1809-0354 \\ Blumenau, v.14, n.3, p.934-959, set./dez. 2019 \\ DOI: http://dx.doi.org/10.7867/1809-0354.2019v14n3p934-959}

à natureza do que difere. Esse retorno do mesmo não favorece a volta do mesmo ao mesmo lugar, mas possibilita que se atribua a mesma coisa ao que ocorre e ao que se diz; ou seja, produz encontro entre acontecimento e sentido. Esse conceito de diferença remete a univocidade e não a unidade. E a univocidade diz que "os existentes são múltiplos e diferentes". (DELEUZE, 1974, p.185).

Por fim, o plano cosmológico, a síntese disjuntiva, as linhas de um eu fendido entre o físicoe o psíquico preparam algo a ser esboçado pelos princípios da cartografia. A própria noção de síntese disjuntiva atua na univocidade como um entre, um trabalho de problematização que precisa ser feito para tirar a maldição da diferença. Dando continuidade a um trabalho com e para a diferença, o sujeito deleuziano se encontra fendido entre contradições lógicas e incompatibilidades ilógicas. É indivíduo rachado que busca apreender a si mesmo.

Quanto ao objeto, há que se entender que a univocidade do múltiplo se dá como acontecimento numa espécie de contra-efetuação: outros "indivíduos como acontecimento não representam outros acontecimentos como indivíduos. Cada indivíduo seria um espelho para a condensação das singularidades, cada mundo uma distância no espelho". (DELEUZE, 1974, p.184). Logo, o acontecimento compõe o indivíduo e, num exercício de unidade disjuntiva, assenta sua singularidade e existência de modo diferente quando afirma algo que o distancia daquilo que ele não é.

Essas elucidações se fazem necessárias para que se possa retomar a tensa relação entre diversidade e o conceito de diferença. Quando atraem o conceito da diferença, as questões da diversidade o fazem para utilizá-lo como oposição ao conceito de identidade - oposição que não nega a identidade, mas a multiplica em seus usos. Ora, diversidade implica a oposição entre identidade e diferença, reivindica um lugar de representação que inclua grupos excluídos nas práticas de significação e nos sistemas simbólicos por meio dos quais os significados produzidos operam posicionamentos que tornam visíveis novos sujeitos. Ocorre que as novas representações produzidas por esse grupo que reivindica inclusão, quando incluído, ampliam o sistema simbólico, operando novas exclusões. Nesse sentido, a diversidade multiplica as identidades e os discursos válidos no sistema de 


\section{Atos de Pesquisa em Educação - ISSN 1809-0354 \\ Blumenau, v.14, n.3, p.934-959, set./dez. 2019 \\ DOI: http://dx.doi.org/10.7867/1809-0354.2019v14n3p934-959}

representação, criando nesse sistema condições, lugares a partir dos quais os indivíduos podem se posicionar e podem falar. (WOODWARD, 2013).

Uma pesquisa em educação que busque tratar da diferença não deve cair na tentação dos dualismos tradicionais, focada na experiência e na experimentação, mas sim ser processo que implica em criar um começo sem condicionantes prévios. Por isso, nem sujeito nem objeto, porque a diferença que Gilles Deleuze aborda não se refere à identidade ou às identidades, mas é a diferença em si mesma. O esforço de sua filosofia é estabelecer um estatuto próprio da diferença (HARDT, 1996; GIL, 2008). Desposar a natureza do sensível sem traí-lo, sem criar um mundo paralelo que o antecede e o condiciona, tal como fizeram as filosofias da tradição, desde Platão. Segundo Gil, na obra Diferença e repetição fica claro o esforço em definir a diferença em seu estatuto próprio. Deve-se a isso o fato de que a

[...] crítica das noções de "representação", "conceito reflexivo" ou "ideias" (no sentido platônico, kantiano ou mesmo husserliano) enquanto noções incapazes de captar o real diferencial em si mesmo conduz Deleuze à destruição de uma "imagem de pensamento" que constituiu a ossatura de muitas filosofias do passado: uma imagem estática do Ser, um edifício bem arquitetado, fundado, com distribuições bem definidas por categorias rígidas das regiões de Ser, aonde o pensar é, antes de mais, fundar através do Mesmo e do Idêntico. (GIL, 2008, p.15).

Essa crítica a uma imagem de pensamento implica numa desconstrução que requer uma reconstrução em outras bases. Diferentes estudos apontam para uma ontologia da diferença na obra de Gilles Deleuze.

\section{FUNDAR UMA LÓGICA IRRACIONAL/ABERRANTE}

Refere Vasconcelos (2005) que os estudos deleuzianos conduzem à ideia de que o pensamento fundante sobre a identidade se sedimenta menos pela teoria das ideias de Platão e mais pela contribuição de Aristóteles ao pensamento ocidental, pois é esse último que realmente funda uma filosofia da representação. A lógica formal aristotélica, cujo conceito mediador é a analogia, permite a representação. 


\section{Atos de Pesquisa em Educação - ISSN 1809-0354 \\ Blumenau, v.14, n.3, p.934-959, set./dez. 2019 \\ DOI: http://dx.doi.org/10.7867/1809-0354.2019v14n3p934-959}

[...]Entretanto, Aristóteles censuraria Platão por não tê-la descoberto antes, partindo o filósofo ateniense diretamente do modelo formal da Ideia à cópia sensível da matéria. Aristóteles, por sua vez, ao subordinar a diferença à oposição, à semelhança e à própria analogia teria garantido a mediação que fez da diferença ao longo da história da filosofia um recalque da identidade. O Ser, mediado pelo plano da identidade, acabou por ser determinado por duas grandes características: tornou-se distributivo e hierárquico, ou seja, distribui-se, equivocadamente, de modo compartilhado, e remete a um sentido primeiro regulando todas as suas emanações (VASCONCELOS, 2005, p.140-141).

Como outros autores estudiosos da obra de Deleuze, Vasconcelos (2005) afirma uma ontologia; ou seja, uma teoria que busca fundar a diferença e seus modos inconstantes, variáveis, subjetivos, sensíveis, limiares com os quais ela se manifesta. Seguindo a perspectiva aberta por Michel Foucault (2005), José Gil (2008), EladioCraia (2009) e François Zourabichvili (2016) defendem de diferentes modos a existência de uma ontologia da diferença na obra de Deleuze. Para esses autores, existe junto à busca de reconstituir os campos empírico e transcendental por meio de novas ordens ou dimensões do tempo e do espaço, uma espécie de lógica da diferença, entre outros elementos que a constituem. Esta

[...] caracteriza-se por o ser se dizer em todas as suasdiferenças, ouseja, ele é a repetição como diferençarepetição que não pode reduzir-se, mecânica ou materialmente, àsexigências do Mesmo e do Idêntico, além de defender quea diferença seja liberada do jugo da identidade e da semelhança. Liberá-la do estado de subordinação àidentidade e à prevalência ao erro que o pensamento darepresentação the outorgou [...]. (VASCONCELOS, 2005,p. 141)

Os princípios kantianos fundam uma noção ontológica na qual o conhecimento posto aqui em analogia com o entendimento dispõe, na Critica da razão pura, de conceitos apriori perfeitamente determinados em vínculo com 0 interesse especulativo; e na "Crítica da razão prática, as ideias da razão[...] encontram-se determinadas pela lei moral; por intermédio dessa lei, a razão determina objetos suprassensíveis que Ihe são submetidos" (DELEUZE, 2010, p.80), induzindo o entendimento a certo exercício de interesse prático. O que se aponta nos princípios kantianos do entendimento é que esses são modos de abordagem que antecipam o presente em um tempo ideal transcendental; no qual o entendimento legisla no interesse especulativo e a razão, no interesse prático, ambos fundados na Crítica da 


\section{Atos de Pesquisa em Educação - ISSN 1809-0354 \\ Blumenau, v.14, n.3, p.934-959, set./dez. 2019 \\ DOI: http://dx.doi.org/10.7867/1809-0354.2019v14n3p934-959}

faculdade de julgar, terceira crítica, que, na verdade, funda as outras duas. (DELEUZE, 2010, p.81).

Subvertendo a noção ontológica kantiana que, junto a Descartes e Hegel, dá base à epistemologia moderna, Deleuze busca fundar a diferença no tempo presente, fazendo com que aquilo que se procura conhecer do diferente derive em conceito de espaço ligado à geografia ou a uma geofilosofia. Algo que diga da terra como lugar do pensamento e do tempo como movimento. Rompendo com Kant e com os demais modernos, como disse Lapoujade (2015), Deleuze investe em uma lógica do irracional, do aberrante, que, ao final, é um modo de fundar a diferença, a experiência do diferente, do sensível, do limiar. Daí a necessidade do mapa, da cartografia do registro do movimento que deve permanecer em movimento, uma vez que pertence ao campo do sensível e do que não é estático.

A lógica aberrante de Deleuze desinstala a relação moderna sujeito-objeto, que ainda se utiliza hoje nas pesquisas. A grande questão é o que significa pensar sem imagens anteriores ou como olhar para as coisas que estão acontecendo despindose dos juízos sintéticos a priori. Como fazer uso da intuição bergsoniana que atua na matéria fazendo durar na memória aquilo que pode ser mudança de qualidade para a memória, para efetivação, duração ou manutenção dos dados selecionados na experiência.

O conceito de experiência é muito importante para a filosofia deleuziana, para sua perspectiva metodológica empírico-transcendental. Em Deleuze, pensamento e experiência andam juntos no acontecimento: "o pensamento é possível porque antes de pensar não se sabe o que o pensamento é".(CUNHA, 2011, p.73).O filósofo expressa quepensar é algo que se faz experimentando e problematizando (DELEUZE,2005) as realidades possíveis.Para trabalhar os princípios da cartografia, descritos em Mil platôs I (DELEUZE; GUATTARI,1995), é preciso problematizar o que inquietava Gilles Deleuze em sua produção filosófica - questões que, na reunião com Felix Guattari, extravasaram em obra conjunta perturbadora. Os princípios do rizoma, que são também os princípios da cartografia, abrem essa obra dividida em cinco partes na versão brasileira. Os autores começam olivro dizendo que o pensamento tecido nele e através dele busca fundar uma nova concepção, na qual tudo é 


\section{Atos de Pesquisa em Educação - ISSN 1809-0354 \\ Blumenau, v.14, n.3, p.934-959, set./dez. 2019 \\ DOI: http://dx.doi.org/10.7867/1809-0354.2019v14n3p934-959}

951

coextensivo a tudo; a experiência, a existência, o entendimento, tudo coexiste ao modo de uma geofilosofia. Filosofia que traça mapas para salvaguardar a possibilidade de uma diferença pura.

Incomodava Gilles Deleuze, antes mesmo do encontro com Guattari, uma imagem de pensamento (o pensamento da tradição filosófica moderna a que acima se fez referência) que funda o pensar antes da experiência que o reclama, antes do acontecimento que o interpela. Segundo Hardt (1996), no contexto em que essa filosofia está sendo produzida há um domínio de uma teoria continental, a fundação hegeliana. Um dos primeiros a fazer um estudo dedicado do pensamento deleuziano, Hardt analisou que "[...] as primeiras obras de Gilles Deleuze são exemplares de uma geração de pós-estruturalistas" (HARDT, 1996,p.10), que concentram um antihegelianismo. Deleuze e Guattari, falando da própria obra, comentam que se "OAntiÉdipo tinha uma ambição kantiana: era preciso tentar uma Crítica da Razão Pura no nível de inconsciente [...].Mil platôs se baseia, ao contrário, em uma ambição póskantiana (apesar de deliberadamente anti-hegeliana)". (DELEUZE; GUATTARI, 1995, p.8). Dizem ainda, nesse Prefácio à edição italiana, que em Mil platôs, quando tratam do "homem dos lobos" ou do "um só ou vários lobos", estão dando adeus à psicanálise e tentando mostrar que as multiplicidades das quais tratam são do tipo que ultrapassam a "distinção entre consciente e inconsciente, entre a natureza e a história, o corpo e a alma". (DELEUZE; GUATTARI,1995, p.8).

A dupla de autores deixa claro que as multiplicidades que problematizam nessa obra gigante não referem a nenhuma unidade anterior, a nenhuma totalidade, nem referem a algum sujeito. Daí a necessidade de proporem princípios, pois estes atuam como uma espécie de norte (ou sul)dessa obra toda que traçam em conjunto. Os princípios são a produção de um pensamento que entende as multiplicidades como formadas por seis elementos. O primeiro elemento que, para os pensadores, forma a multiplicidade são as singularidades; o segundo, as relações do tipo devires que essas produzem; o terceiro, que elas acontecem ao modo de hecceidades(essas entendidas como individuações em sujeito); o quarto elemento que compõe essa concepção de multiplicidade articula que ela se dá em um espaço-tempo ou em espaços-tempos livres; o quinto elemento é que ela se organiza no modelo de um rizoma (se opõe à 


\section{Atos de Pesquisa em Educação - ISSN 1809-0354 \\ Blumenau, v.14, n.3, p.934-959, set./dez. 2019 \\ DOI: http://dx.doi.org/10.7867/1809-0354.2019v14n3p934-959}

arborescência); e, por fim, o sexto elemento evoca a multiplicidade como plano de composição ao modo de platôs, zonas de intensidade contínua atravessada porvetores que constituem territórios e graus de desterritorialização (DELEUZE;GUATTARI,1995).

Basicamente, esses seis elementos precedem os princípios de uma cartografia ou de uma pesquisa cartográfica. Entretanto, é preciso esmiuçá-los e identificar que relações eles estabelecem enquanto princípios com outras abordagens sobre a diferença na obra de Gilles Deleuze, uma vez que esse filósofo buscou novos caminhos para a criação de conceitos e a produção de conhecimentos. Gil (2008) vai dizer que em O que é filosofia?, obra posterior,que Deleuze e Guattari (1992) incluem um sétimo elemento ou algo que conecta os demais constitutivos dessa ontologia da diferença. Trata-se do plano de imanência. O plano de imanência não é um conceito dos conceitos, como dizem os filósofos, mas um planômeno. Um lugar de conexão onde pode ser expressa certa territorialidade na qual os conceitos, ao modo de vagas múltiplas, entram em relação; o "[...] problema do pensamento é a velocidade infinita, mas essa precisa de um meio que se mova em si mesmo infinitamente, o plano, o vazio, o horizonte".(DELEUZE; GUATTARI,1992, p.51).

Conceito e meio são necessários para compor uma imagem de pensamento que norteie o processo, pois o plano será a imagem que o pensamento tem para se orientar. Como disse Zourabichvili (2005), escrevemos e falamos literalmente, mas para se chegar a um entendimento é preciso construir e mostrar as relações. Em texto que comenta a questão da literalidade em Deleuze, o autor assevera que esse conceito do "[...]plano de imanência começa a adquirir consistência, uma vez que ele se define como a transversal de todos os domínios tidos como próprios, em que tudo pode entrar em relação com tudo". (ZOURABICHVILI, 2005, p.1319). Essa consistência refere à capacidade que o plano possui de conjugar pensamento e experiência. Essa "filosofia é, pois, propriamente filosófica enquanto pensamento da experiência ou, o que vem a dar no mesmo, enquanto pensamento da imanência". (ZOURABICHVILI, 2005, p.1319).

A metodologia cartográfica implica um plano de conexões em que pensamento e vida, indivíduo e grupo formam linhas paralelas e transversais; nas quais pensar 


\section{Atos de Pesquisa em Educação - ISSN 1809-0354 \\ Blumenau, v.14, n.3, p.934-959, set./dez. 2019 \\ DOI: http://dx.doi.org/10.7867/1809-0354.2019v14n3p934-959}

produz significações que têm a ver com demarcar um território, ético, político, estético, filosófico, pedagógico, étnico, cultural. Pensar em Gilles Deleuze e Felix Guattari conduz o corpo a seus territórios de existir. Logo, dar forma ao pensamento por meio do estudo, da escrita ou da criação na obra de arte implica em se implicar no que está propondo, sugere expressar devires.Há algo vital no pensamento deleuziano que acompanha as três fases da sua produção. Parafraseando Lapoujade, não é que a vida insufle a lógica, como se fosse um vento de irracionalidade que, ausente, lhe faz falta; "[...] ao contrário, é que as potências da vida produzem incessantemente novas lógicas que nos submetem à irracionalidade delas". (LAPOUJADE, 2015, p.14). As intervenções conceituais são movimentos que operam sempre na emergência da vida, nas fissuras que brotam da busca de traduzir o sentido vivido que escapa ao pensar o tempo todo. Uma passagem da Lógica do sentido talvez esclareça ou induza ao rizoma, à cartografia.

O sentido aparece e atua na superfície, pelo menos se soubermos convenientemente, de maneira a formar letras de poeira ou como um vapor sobre o vidro em que o dedo pode escrever [...] O filósofo não é mais o ser das cavernas, nem a alma ou o pássaro de Platão, mas o animal chato das superfícies, o carrapato, o piolho. (DELEUZE, 1974).

As singularidades, o acontecimento, as séries, entre outros conceitos que já estavam propostos na filosofia de Deleuze, compõem um processo do múltiplo que se arrisca a manter em estado de multiplicidade. Daí a cartografia ser um modo de acompanhar os efeitos das multiplicidades na superfície, mesmo que ao final a composição de tais efeitos aponte para o sobrevoo que é próprio do conceito.Como disseram Deleuze e Guattari em O que é filosofia?,"cada conceito remete a outros conceitos, não somente em sua história, mas em seu devir ou suas conexões presentes. Cada conceito tem componentes que podem ser, por sua vez, tomados como conceitos". (DELEUZE; GUATTARI, 1992, p. 31). 


\section{Atos de Pesquisa em Educação - ISSN 1809-0354 \\ Blumenau, v.14, n.3, p.934-959, set./dez. 2019 \\ DOI: http://dx.doi.org/10.7867/1809-0354.2019v14n3p934-959}

954

\section{O QUE QUER A PESQUISA CARTOGRÁFICA? CONSIDERAÇÕES EM PROCESSO}

A pesquisa cartográfica busca uma criação, proposição ou construção de processos com a diferença, que fujam da simples representação ou codificação, que possibilitem uma abordagem que não fixa nem venha a fixar ou codificar $\mathrm{o}$ isto ou o aquilo que se quer analisar, referenciar ou trazer a uma forma de linguagem. "A pesquisa cartográfica é menos a descrição de estados de coisas do que o acompanhamento de processos". (ALVAREZ; PASSOS, 2009, p.141). Ao trabalhar a diferença é preciso considerar o lugar em que a própria pesquisa e o pesquisador se colocam, pois fugir à representação significa deixar de agir,

[...] como se tivéssemos um eu, como se fôssemos o centro, a fonte e o piloto do processo de conhecimento. $O$ que prevalece é a crença de que 0 conhecimento é configurado pelos esquemas recognitivos, pelas regras e pelo saber anterior. Seja fundamentando o conhecimento nas formas de um mundo preexistente, seja na forma do sujeito cognoscente, a atitude realista e a idealista/individualista apresentam-se como duas faces da mesma política da recognição, que toma o conhecimento como uma questão de representação. (KASTRUP,2005,p.1281).

Tendo por objetivo esclarecer sobre os usos possíveis dessa metodologia de pesquisa, discute-se a proposição dos princípios e sua relação com o pensamento filosófico deleuziano. Com que intenção esses princípios se forjam e como exercem um por meio de ou um entre isso e aquilo para que seus procedimentos potencializem as passagens para a construção de um objeto de pesquisa?

Pesquisar a diferença, especialmente na educação, envolve a desconstrução de arquétipos e estruturas que vêm da tradição identitária, na qual alguns modelos de saber e poder se conformaram em rotinas. Nesse sentido, interessa que se possa pensar em que momento esse conceito de diferença passa a ter destaque, na obra filosófica de Gilles Deleuze; para além de intuir que o cenário francês convoca o pensador à demanda do conceito (DOSSE, 2010), também se quer tratar do encontro de Deleuze com o psicanalista Felix Guattari, e das consequências desse encontro. A obra produzida conjuntamente renova questões da diferença e, enquanto conceito, 


\section{Atos de Pesquisa em Educação - ISSN 1809-0354 \\ Blumenau, v.14, n.3, p.934-959, set./dez. 2019 \\ DOI: http://dx.doi.org/10.7867/1809-0354.2019v14n3p934-959}

essa nova abordagem compõenão um método ou uma direção a seguir, com início, meio e fim pré-determinados. A cartografia entendida como uma metodologia refere a processo investigativo aberto, sobreposto, que caminha em várias direções; é mapa que se delineia aberto a cortes e recortes de linhas, que se dobram e desdobram orientadas pelo sentido da pesquisa. A presunção de uma metodologia cartográfica ou rizomática, para a qual os autores destacam princípios, caracteriza o método cartográfico/rizomático.

Mesmo não sendo equivalentes enquanto conceito, termo ou significado, diversidade e diferença costumam se apresentar muito próximas para aqueles que trabalham com os temas ligados a sexualidade, gênero, raça, cultura, etnia, necessidades especiais, direitos humanos, imigração, entre outros. Vistos de perto, esses conceitos se apresentam transversais nas concepções, práticas e políticas que se impõem nos debates entre cultura e natureza, nos ambientes institucionais, nas disputas entre o público e o privado que compõem os territórios da rotina e conformam os cronogramas dos deveres e as pautas dos direitos.

Diversidade e diferença nos afetam de um ou de outro modo, uma vez que a diversidade convive com uma noção cuja representação suaviza as questões que dão origem aos grupos que nela se agrupam. No temor de que a diversidade tenha se tornado um conceito guarda-chuva, no qual as diferenças se protegem obscurecidas e distantes daquilo que as origina, nas pautas em que o conceito de diversidade se propõe como uma oposição à noção de uma identidade centralizadora, vinda de uma cultura que evoca um modo igualitário de ser. Por conseguinte, a existência do diverso pode estar sendo compreendida como a experiência de alguém que é contra os elementos que compõem a cultura matriz ocidental, cultura que impõe um modelo identitário eurocêntrico, falocêntrico, sexista, branco, racional, cristão sobre os modos de existir e em relação a outras culturas e suas diferentes identidades.

Pode-se dizer que o pensamento pós-estruturalista, no qual a filosofia deleuziana se encaixa, entende que essa oposição diversidade $\mathrm{x}$ identidade é negociada. A diversidade,em certo sentido da linguagem e do senso comum, aproxima-se da diferença, aponta para algo que ela forçosamente traz consigo como oposição a algo; implica em compreendê-la ao modo de superação ou síntese de 


\section{Atos de Pesquisa em Educação - ISSN 1809-0354 \\ Blumenau, v.14, n.3, p.934-959, set./dez. 2019 \\ DOI: http://dx.doi.org/10.7867/1809-0354.2019v14n3p934-959}

oposição binária, tal como o faz a oposição dialética. Quando a diversidade coloca a diferença como oposição, traz ou atrai para o diferente a comparação de uma identidade prévia, pressuposta, anterior. Deixa ou permite que a identidade funde a diferença e a submeta aos seus princípios. Tudo bem que a diferença atraia o sentido do múltiplo e com isso atraia também outros sentidos, como os citados acima - afinal, o diferente inclui as multiplicidades. Entretanto, esse tipo de oposição entre ser e não ser, tese e antítese, não é rupturante, uma vez que substituir a identidade ou opô-la à diferença envolve um entendimento no qual a diversidade apenas substitui o uno pelo múltiplo, sem alterar os elementos básicos que fundamentam essa relação. Logo, a unidade do uno, nesse tipo de oposição binária, multiplica algo que permanece sendo o mesmo, camuflado, referindo ao mesmo numa hierarquia em que o múltiplo se compõe de muitos falsos idênticos subjugados.

Temas, situações e contextos, ligados aos ambientes institucionais e fora deles, têm produzido tradutores, intérpretes, autores, sujeitos inquietos, educadores pensadores, artistas do estranhamento, gente que tenta criar modos de articular, pronunciar, descrever o que é vivível e nem sempre visível, em nome do sentimento e de uma quase imposição da sensibilizada, nomeada diferença. Mas, afinal, como trabalhar com a diferença sem codificá-la, sem tirar dela seu fluxo diferenciante, sem cortar seus movimentos aberrantes? Seria a cartografia um modo de expressão dos processos e de conexão entre o conceito de diferença e o vivido na experiência do que difere? O conceito de diferença é provocativo e exige certo atravessamento do entressentido das coisas, conexões, laços, diagramas, mapas, linhas; é conceito que agrupa e refere a um modo especialmente humano de compartilhar aquilo que não se conforma ao que está posto ordinariamente.Daí a exigência desse mapa aberto, fluído, permeado de multiplicidades, singularidades e conexões sempre por fazer.

\section{CLAUDIA MADRUGA CUNHA}

Doutora em Educação. Pós-Doutora em Educação pela Universidade do Porto (UP/Portugal). Atua no Setor de Educação Profissional e Tecnológica/SEPT e nos programas de Pós-Graduação em Educação, Mestrado e Doutorado em 


\section{Atos de Pesquisa em Educação - ISSN 1809-0354 \\ Blumenau, v.14, n.3, p.934-959, set./dez. 2019 \\ DOI: http://dx.doi.org/10.7867/1809-0354.2019v14n3p934-959}

Educação/PPGE-Edu e no Programa de Mestrado Profissional: Teoria e Prática de Ensino/PPGE:Mp da Universidade Federal do Paraná -UFPR.

\section{REFERÊNCIAS}

ALVAREZ,J.; PASSOS, E. Cartografar é habitar um território existencial.In: KASTRUP, V.; PASSOS, E; ESCÓSSIA, L. da (Org.). Pistas do método da cartografia: pesquisa-intervenção e produção de subjetividade. Porto Alegre: Sulina, 2009.

CRAIA, E. O virtual: destino da ontologia de Gilles Deleuze. Revista Filosofia Aurora.

Curitiba, v. 21, n. 28, p. 107-123, 2009. Disponível em: https://periodicos.pucpr.br/index.php/aurora/article/viewFile/1150/1075. Acesso em: mar. 2019.

CUNHA, C. M. Filosofia Rizoma: metamorfoses do pensar. Curitiba: CRV, 2011.

DELEUZE, G. Lógica do sentido. Tradução de L. R. S. Fortes. São Paulo: Perspectiva, 1974.

DELEUZE, G. Conversações. Tradução de P. P. Pelbart. São Paulo: Editora 34, 1992.

DELEUZE, G. Bergsonismo. Tradução de L. B. L. Orlandi. São Paulo: Editora 34, 1999.

DELEUZE, G. Diferença e Repetição. Tradução de L. Orlandi e R. Machado. Lisboa: Relógio D’Água, 2000a.

DELEUZE, G. A filosofia crítica de Kant. Tradução de G. Franco. Lisboa: Edições 70, 2000b.

DELEUZE, G. Empirismo e subjetividade. Ensaio sobre a natureza humana segundo Hume. Tradução de L. Orlandi. São Paulo: Editora 34, 2001.

DELEUZE, G. Foucault. Tradução de R. Ribeiro. São Paulo: Brasiliense, 2005.

DELEUZE, G. A ideia da gênese na estética de Kant. In: DELEUZE, G. A ilha desertae outros textos. Tradução de L. Orlandi e R. Machado. São Paulo: Iluminuras, 2010.

DELEUZE, G. A concepção da diferença em Bergson. In: DELEUZE, G. A ilha desertae outros textos. Tradução de L. Orlandi e R. Machado. São Paulo: Iluminuras, 2010. 


\section{Atos de Pesquisa em Educação - ISSN 1809-0354 \\ Blumenau, v.14, n.3, p.934-959, set./dez. 2019 \\ DOI: http://dx.doi.org/10.7867/1809-0354.2019v14n3p934-959}

DELEUZE, G.; GUATTARI, F. O que é Filosofia? Tradução de B. Prado JR. e A. A. Muñoz. Rio de Janeiro: Editora 34, 1992.

DELEUZE, G.; GUATTARI, F. Mil platôs: capitalismo e esquizofrenia. Tradução de A. Guerra Neto e C. P. Costa. São Paulo: Editora 34, 1995. v. 1.

DIAS, S. Lógica do acontecimento: Introdução à filosofia de Deleuze. Lisboa: Sistema Solar, 2012.

DOSSE, F. Gilles Deleuze e Felix Guattari: biografia cruzada. Tradução de F. Murad. Porto Alegre: Artmed, 2010.

FOUCAULT, Michel. Arqueologia das ciências e história dos sistemas de pensamento: ditos \& escritos II. Tradução de E. Monteiro. Rio de Janeiro: Forense Universitária, 2005

GIL, J. O imperceptível devir da imanência. Lisboa: Relógio Dágua, 2008.

GUATTARI, F.; ROLNIK, S. Micropolítica: cartografias do desejo. 12. ed. Rio de Janeiro: Vozes, 2013.

HARDT, M. Gilles Deleuze: um aprendizado em filosofia. Tradução de S. Cavendish. São Paulo: Editora 34, 1996.

KASTRUP, V. Políticas cognitivas na formação do professor e o problema do devirmestre. Educação e Sociedade. Campinas, v. 26, n. 93, p. 1273-1288, dez. 2005. Disponível em: https://social.stoa.usp.br/articles/0015/3774/Formacao_do_Professor_e_DevirMestre.pdf. Acesso em: mar. 2019.

KASTRUP, V.; PASSOS, E. Cartografar é traçar um plano comum. Fractal, Rev. Psicol., v. 25, n. 2, p. 263-280, Maio/Ago. 2013.Disponível em: http://www.scielo.br/scielo.php?pid=S1984-02922013000200004\&script 02922013000200004 . Acesso em: mar. 2019.

LAPOUJADE, D. Deleuze, os movimentos aberrantes. Tradução de L. G. dos Santos. São Paulo: N-1 edições, 2015.

MACHADO, R. Deleuze, a arte e a filosofia. 2. ed. Rio de Janeiro: Zahar, 2010.

SANTOS, Z. A. dos. A geofilosofia de Deleuze e Guattari. 2013. Tese (doutorado) Instituto de Filosofia e Ciências Humanas e EcoleDoctorale ED 138 Lettres, Langues. Unicamp, Campinas. 


\section{Atos de Pesquisa em Educação - ISSN 1809-0354 \\ Blumenau, v.14, n.3, p.934-959, set./dez. 2019 \\ DOI: http://dx.doi.org/10.7867/1809-0354.2019v14n3p934-959}

SIMONDON, G. A gênese do indivíduo. In: GUATTARI, F. et al. O reencantamento do concreto. Cadernos de Subjetividade.Tradução de I. Medeiros. São Paulo: PUC HUCITEC, 2003.

VASCONCELLOS, J. A ontologia do devir de Gilles Deleuze. Kalagatos. Revista de Filosofia do Mestrado Acadêmico em Filosofia da UECE, Fortaleza, v. 2, n. 4, p.

137-167, 2005.Disponível

em: https://www.academia.edu/4863633/A_ontologia_do_devir_de_Gilles_Deleuze. Acesso em: mar. 2019.

WOODWARD, K. Identidade e diferença: uma introdução teórica e conceitual. In: TOMAZ, T. (Org.). Identidade e diferença: a perspectiva dos estudos culturais. Tradução de T. T. da Silva. 12. ed. São Paulo: Vozes. 2013.

ZOURABICHVILI, F. O vocabulário de Deleuze. Tradução de A. Telles. Rio de Janeiro: Relume Dumará, 2004.

ZOURABICHVILI, F. Deleuze e a questão da literaridade. Revista Educ. Soc., Campinas, vol. 26, n. 93, p. 1309-1321, set./dez. 2005. Disponível em: http://www.cedes.unicamp.br. Acesso em: 08 mar. 2019.

ZOURABICHVILI, F. Deleuze, uma filosofia do acontecimento. Tradução de L B. L. Orlandi. São Paulo: Editora 34, 2016. 